\title{
Research on air legislation requirements necessary for training competent commercial pilot for the purpose of sustainable development of the civil aviation of the Russian federation
}

\author{
Sergey Lobar ${ }^{*}$, Polina Myagkova, and Mikhail Pashkov \\ Saint Petersburg State University of Civil Aviation, st. Pilots, 38, 196210 Saint-Petersburg, Russian \\ Federation
}

\begin{abstract}
The article discusses the norms of civil aviation legislation governing the training of commercial aircraft pilotsfor the purpose of sustainable development of the civil aviation of the Russian Federation. The analysis of ICAO standards and recommended practices in the field of professional training of flight crew members was carried out in order to: research the practice of using the regulatory framework in the development and implementation of training programs for flight crew members of civil aviation of the Russian Federation; - identify of shortcomings in the regulatory framework in the field of professional training of flight crew members; - develop recommendations for improving the air legislation of the Russian Federation, taking into account the requirements of ICAO.
\end{abstract}

\section{Introduction}

Improving the level of flight safety in the global air transport system is the fundamental and most important strategic goal of ICAO, which is constantly working to ensure and improve the performance of the state of flight safety using:

- $\quad$ flight safety monitoring;

- safety analysis;

- implementation of programs in the field of flight safety.

Figure 1 presents the results of a statistical analysis of the data on the categories of aviation accidents from 2014 to 2018, which indicate that the problem of reducing the risk of events Runway Safety (RS), Loss of control (LOC-I) and Controlled Flight Into Terrain (CFIT) continues to be relevant. [1].

The analysis showed that in 2014-2018, 50\% of accidents were classified as RS events. The other two categories account for only 4\% (LOC-I) and $2.98 \%$ (CFIT) of all aircraft accidents worldwide. However, $38 \%$ of fatalities worldwide, which are attributable to LOC-I and CFIT events, indicate the importance of continuing to implement preventive

\footnotetext{
*Corresponding author: $\underline{\text { losegr@mail.ru }}$
} 
measures to prevent both the specified categories of high-risk accidents and other complex and emergency situations arising during the flight operation of aircraft.

In the Russian Federation, during the period from 2014 to 2018, there were 14 accidents of categories CFIT, LOC-I and RS, which is $88 \%$ of the total number of accidents during regular passenger traffic by aircraft weighing more than $5700 \mathrm{~kg}$ [2].

Comparative analysis of the data shows that in the Russian Federation, as well as in general in ICAO, the problem of reducing the risk of RS, LOC-I and CFIT events remains urgent.

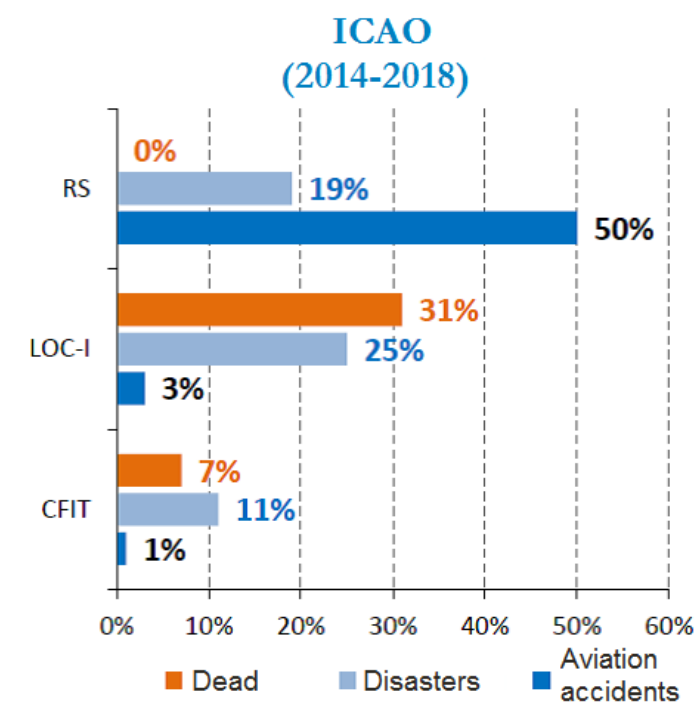

Fig. 1.High risk accident categories worldwide in scheduled traffic of aircraft weighing more than $5700 \mathrm{~kg}(2014-2018$.)

\section{Methods and types of the air law requirements research}

In the presented study, the authors were guided by the tasks set forth in the guidance documents of the ICAO, the Interstate Aviation Committee, and the Ministry of Transport of the Russian Federation in the field of training commercial aviation pilots.

The study is based on the use of modern methods of scientific knowledge: systeminformation analysis, statistical methods, methods of expert assessment.

The research was also based on the conceptual provisions of the methods for identifying hazardous factors and their impact on flight safety, set out in Doc 9859 (AN / 474) [3], namely:

1. A reactive approach methodology involving the analysis of past results or events, in particular the hazards identified during the investigation of aviation events;

2. A proactive approach methodology, providing for the search for hazardous factors in existing processes, in particular, in the regulatory framework and the system of professional training of flight crew members;

3. A predictive approach methodology, providing for the analysis of system processes in order to identify potential hazards in the future and take measures to reduce them. 


\section{Analysis of ICAO regulations in the field of professional training of a commercial pilot}

We will carry out a systemic and informational analysis of the ICAO regulatory documents governing the system of forming the competencies of a commercial aircraft pilot.

1. Appendix 1 "License Issuanceto Aviation Personnel" to the Convention on International Civil Aviation [4].

This document notes that in order to achieve the required level of knowledge, skills and abilities of flight crew members, it is necessary to ensure the harmonization of the professional training system with the requirements for the issuance of licenses to aviation personnel, in particular, a pilot of a commercial aircraft.

A candidate for a commercial pilot license in terms of qualification level must have the appropriate knowledge, skills and experience in aircraft flight operation.

Analysis of ICAO requirements for maintaining the level of competence of flight crew members showed that:

- firstly, ICAO proposes to use a systematic approach to improving the safety of flight operation of aircraft based on a comprehensive analysis of its own flights, as well as data on the state of flight safety for this type of aircraft in the ICAO member states.

To implement this recommendation, it is necessary to use the IATA Evidence-Based Training Manual (EBT) [5]. However, when introducing this program in the civil aviation of the Russian Federation, operators and Aviation Training Centers face such problems as:

- completeness and objectivity of the safety data used;

- $\quad$ ability to use safety data;

- objectivity of the level of training of the instructor and the quality of his work;

- risks associated with changes in the traditional methodology and scope of training;

- regulatory aspects of EBT adoption;

- $\quad$ secondly, ICAO proposes to use test flights on an aircraft or state-approved flight simulation training devices for a reliable assessment of the level of skills and abilities of a commercial aircraft pilot. In doing so, reference is made to Doc. 9625 (AN / 938) «Manual on qualification criteria for flight simulation training devices. Volume 1. Aircraft», CAO [6].

However, Doc. 9625 does not clearly defineby whom, in what time frame, and at what stage the qualification assessment of the aviation simulator is carried out.

2. Doc. 7192 (AN / 857) "Training Manual" [7]

\subsection{Part A-1 General Provisions (hereinafter - Part A-1)}

Part A-1 has not updated since February 15, 1988, the date of application of its registered amendment, which leaves an imprint on some of the terms, definitions and wording used in this document. Therefore, further comments of the authors are presented using the terminology that currently exists in the education system and the system of training aviation personnel in the Russian Federation in the Russian Federation.

The basic principles of professional training of flight crew members, formulated in the "Training Manual" more than 30 years ago, correspond to the requirements of the current system of training for flight crew members, including training of pilots for highly automated aircraft, which is confirmed by the following provisions of Part A-1:

- firstly, the document clearly and unambiguously defines the components of the training system for flight crew members:

1) training program;

2) resources for training - teaching and instructor personnel, equipment, etc .;

3) an effective training system - legal, organizational, methodological support of the educational process; 
- secondly, the content of the methodological support of the educational process is described in detail:

1) recommendations are presented on the methodology for preparing a teacher for classes and conducting classes;

2) the main ways of the interconnected activity of the teacher (instructor) and the listener are identified to achieve the goal of learning - the formation of stable knowledge, skills and abilities in the student;

3) general rules for the control of knowledge, skills, abilities, as well as requirements for the procedure for the development of banks of test items are determined.

Taking into account the fact that one of the main directions of improving the system for training pilots of modern highly automated aircraft in civil aviation of the Russian Federation is the introduction of modern automated training systems and technical training aids, it should be noted that Part A-1 of the Training Manual states:

- with regard to the use of audiovisual means of demonstrating educational materials, including automated training systems:

1) the rational use of audiovisual means, both in the process of theoretical training and in the process of practical training of flight crew members, is a necessary condition for achieving the required level of knowledge and skills in the training of pilots in a given time;

2) the effectiveness of the use of audiovisual means is largely determined by the qualifications of teaching and instructor personnel;

- regarding the use of technical training aids:

1) technical training aids, in particular flight simulation training devices, are an effective means of testing the level of skills and abilities in such an area as piloting;

2) the given flight simulator must be of the appropriate level and meet certain criteria for the qualification assessment of flight simulators.

2.2. Part B-5 Comprehensive training course for commercial pilots (Course No. 236 ICAO) (hereinafter - Part B-5)

The course described in Part B-5 is intended for the initial training of commercial aviation pilots in civil aviation educational institutions in accordance with ICAO standards and recommended practices.

In the description of this course, published in 1985, the positive is that:

- the importance and effectiveness of integrated flight simulators in pilot training was emphasized;

- it was recognized that pilot training programs and methods were developing slowly;

- it was assumed that educational institutions of civil aviation, in particular, aviation training centers, will add to this course in the form of information that meets modern trends in the development of both the aircraft fleet and pilot training methods.

At the same time, in Part B-5:

- firstly, quoting paragraph 1.1.3.2 of Part B-5 “... at present, many centers provide training at a level of scientific and mathematical knowledge that is more appropriate for an aeronautical engineer or meteorologist than for a novice pilot", the role of fundamental knowledge is underestimated during the initial pilot training, which are the basis for mastering applied disciplines such as navigation, aerodynamics, flight operation, flight training methodology and others;

- secondly, in Part B-5 only the need to use flight simulators at various stages of pilot training is indicated, while other technical training aids and automated training systems, especially important in the development of highly automated aircraft, as well as modern methods of training members flight crews are not mentioned at all.

\section{Doc. 9868 "Personnel training" [8]}

This document reflects the requirements for training programs for flight crew members: 
1) qualification system for training and issuance of a multi-crew pilot license (MPL);

2) Evidence-Based Training (EBT);

3) Upset Prevention and Recovery Training (UPRT).

Of particular interest in this document is a systematic approach, both to the methodology for developing training programs for flight crew members, and directly to the organization of the educational process in the aviation training center. It is emphasized that a systematic approach is a guarantee that the pilot will achieve the required qualification level of knowledge, skills and abilities of the pilot due to:

- establishing a list of knowledge, skills and abilities to be achieved;

- determining the best methods to achieve the skill level;

- development of effective tools for assessing the level of qualifications.

Such a systematic approach can be used to improve the pilot training system for highly automated aircraft based on:

- determination of the pilot's competence level, which must be achieved after passing both individual stages and the entire training program based on a comprehensive analysis of the requirements of ICAO, the Russian Federation, a specific operator, flight technical documentation of this type and aircraft modification;

- a reasonable choice of educational technologies, methods, forms and means of training, both for this category of trainees and for a specific pilot, which guarantee the stability of the knowledge, skills and abilities formed and their applicability in real flight conditions;

- using valid, reliable methods of assessing the pilot's competence level.

\section{Doc. 9995 (AN / 497) "Evidence-Based Training Manual" [9]}

The Evidence-Based Training (EBT) program was created out of the need to develop a new paradigm for competency-based training and evidence-based pilot assessment.

Analysis of factual data on accidents with aircraft weighing more than 10 tons (Figure 2), as well as the analysis of 56 special situations on board Airbus 319/320/321, Boeing 737NG, CRJ-200, An-148 aircraft of 6 airlines The Russian Federation was allowed to conclude that to ensure an integrated approach to the prevention of aviation accidents associated with aviation events, including categories RS, LOC-I and CFIT, it is necessary to introduce scientifically sound, technically verified and tested innovations that provide, as an objective assessment of the strengths and weaknesses of the pilot based on the analysis of evidence, and the effectiveness of his professional training to obtain the appropriate qualifications and maintain them at the required level.

The need to implement EBT is also due to:

- active transition of Russian airlines to highly automated aircraft, which leads to a change in the content and methods of implementation of training programs for flight crew members based on a wide range of initial data on flight safety, combined with continuous objective analysis of errors during training for a real understanding of the causes of their occurrence;

- the realization that the effectiveness of a pilot of a highly automated aircraft can only be ensured on the basis of the complementary use of knowledge, skills and abilities, both in the "technical" and "non-technical" areas of qualification.

The basis of the EBT is the development of competencies through exercises. In the competence-based training system, the goal of any exercise is to analyze and correct (if necessary) the balance of pilot competencies, ensuring sufficient reliability of the entire crew.

The EBT philosophy is that FSTDs of the appropriate level should be used as much as possible to assess and develop crew competencies. Crews must face various situations that they may encounter while flying with an airline. 
It is proposed to use an innovative approach to training pilots of modern EAC, based on the formation of competencies at the same time at all stages of training.

The main role here is played by Attitude - an unconscious psychological state, an internal quality of a subject based on his previous experience, a predisposition to a certain activity in a certain situation [10].

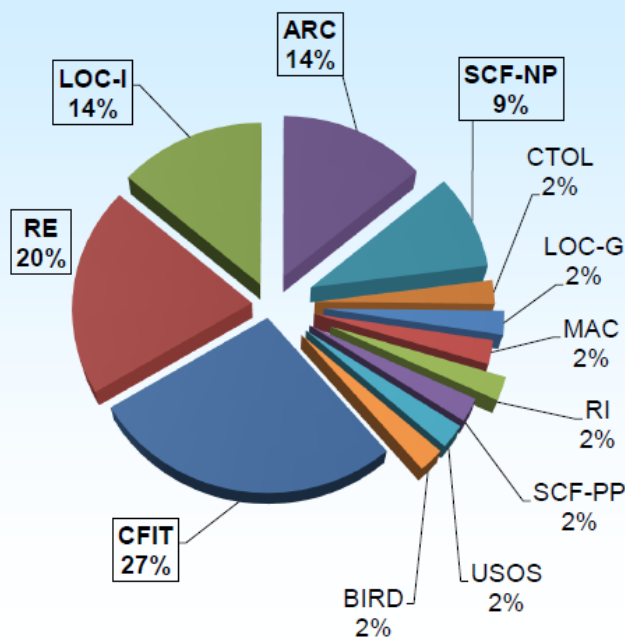

CFIT - Controlled Flight Into or Toward Terrain RE - Runway Excursion

LOC-I - Loss of Control-Inflight

ARC - Abnormal Runway Contact

SCF-NP - System/Component Failure or Malfunction (Non-Powerplant)

CTOL - Collision With Obstacle(s) During TakeOff or Landing

LOC-G - Loss of Control-Ground

MAC - Airprox/TCAS Alert/Loss of Separation/Near Midair

RI - Runway Incursion

SCF-PP - System/Component Failure or Malfunction (Non-Powerplant)

USOS - Undershoot/Overshoot

BIRD - Occurrences involving collisions/near collisions with bird(s)

Fig. 2.Categories of accidents with aircraft weighing more than 10 tons (2001 - 2017)

\section{Conclusions}

The study of the regulatory framework in the field of training flight crew members allowed the authors to:

1) determine the main reasons that complicate the use of these documents in the practice of developing, approving and using training programs for flight crew members of civil aviation of the Russian Federation, including pilots of highly automated aircraft, namely:

- the presence of contradictions in certain provisions of the legislation that complicate the process of development, approval and implementation of training programs for aviation personnel and, in particular, flight crew members;

- problems associated with the adaptation of the ICAO regulatory framework in the field of training of flight crew members based on the analysis of actual data (EBT) to the air legislation of the Russian Federation and the implementation of this program in the pilot training system in the Russian Federation;

- the absence in the Russian Federation of both standard additional professional programs in the field of pilot training, and any methodological recommendations, other documents approved at the federal level in the field of pilot retraining;

2) determine the directions for improving the air legislation of ICAO and the Russian Federation, namely:

- logical systematization of the regulatory framework;

- harmonization of the regulatory framework of ICAO and the Russian Federation;

- development of standard additional professional programs in the field of training for flight crew members. 


\section{Acknowledgements}

The article was prepared in the specialization 05.22.14 - "Operation of air transport".

\section{References}

1. ICAO, www.icao.int

2. Analysis of the state of flight safety in civil aviation of the Russian Federation in 2018. Federal Air Transport Agency of the Russian Federation, 89 (2019)

3. Safety Management Manual, ICAO, 300 (2013)

4. Convention on International Civil Aviation, Appendix 1, 11, 150 (2011)

5. Training of personnel based on analysis of actual data. Implementation guide, IATA, 223 (2104)

6. Manual on qualification criteria for flight simulation training devices, 1, Aircraft, ICAO, 744 (2009)

7. Training Manual, ICAO, 214 (2011)

8. Personnel training, ICAO, 254 (2016)

9. Evidence-Based Training Manual, ICAO, 170 (2013)

10. D. V. Gander, Professional psychopedagogy, 336(2007) 